
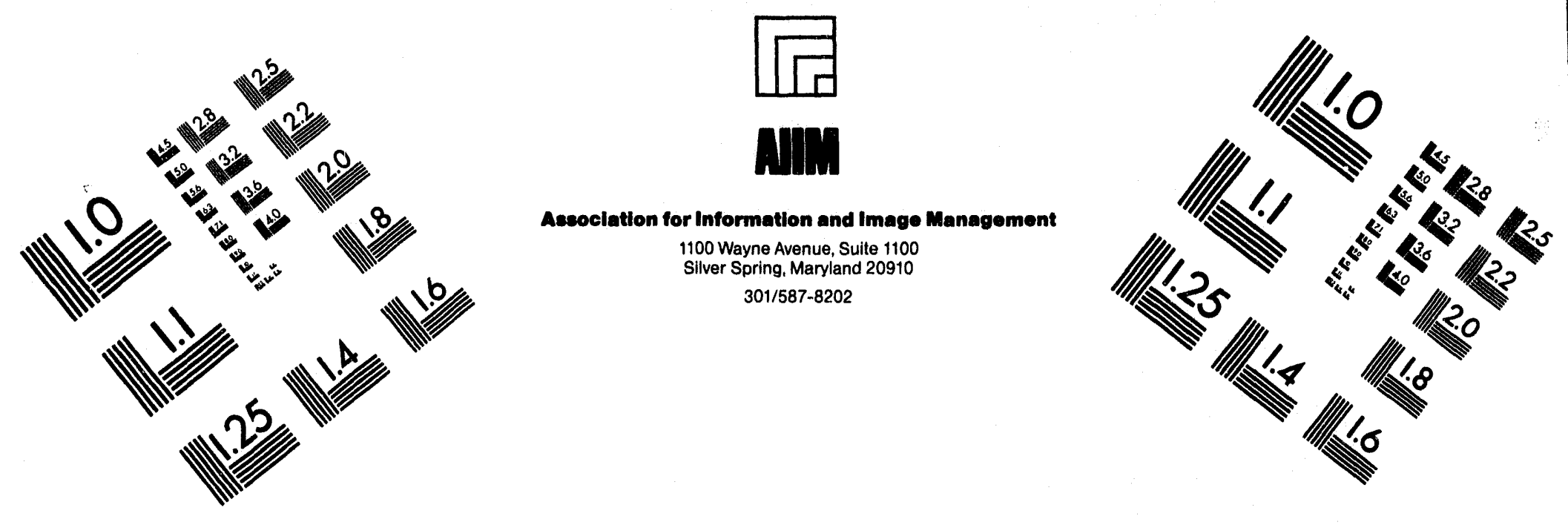

\title{
Centimeter
}

$\begin{array}{llllllllllllllll}1 & 2 & 3 & 4 & 5 & 6 & 7 & 8 & 9 & 10 & 11 & 12 & 13 & 14 & 15 & \mathrm{~mm}\end{array}$

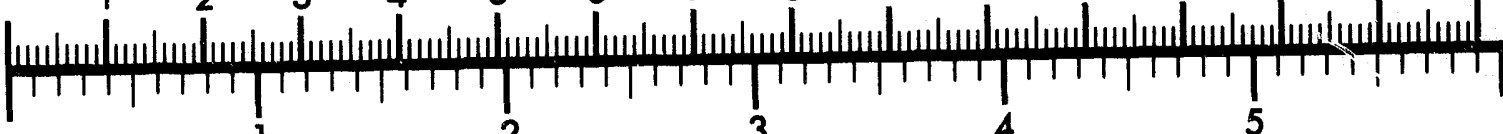
Inches

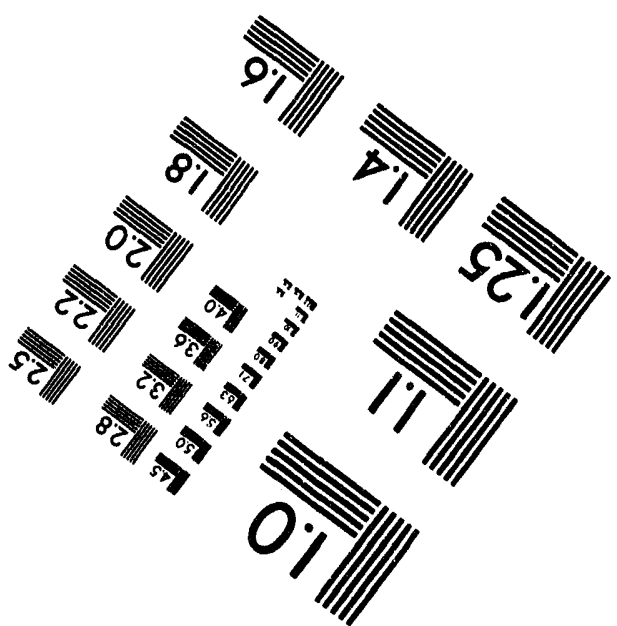

MANUFACTURED TO AIIM STANDARDS

BY APPLIED IMAGE, INC.

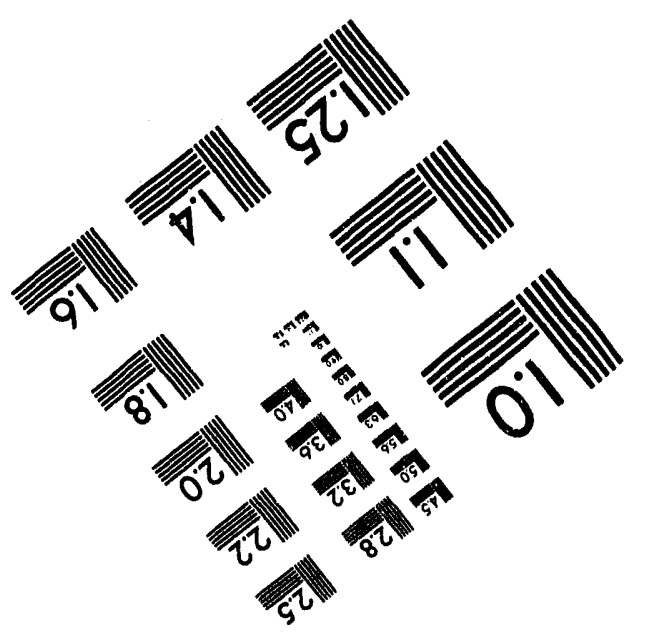



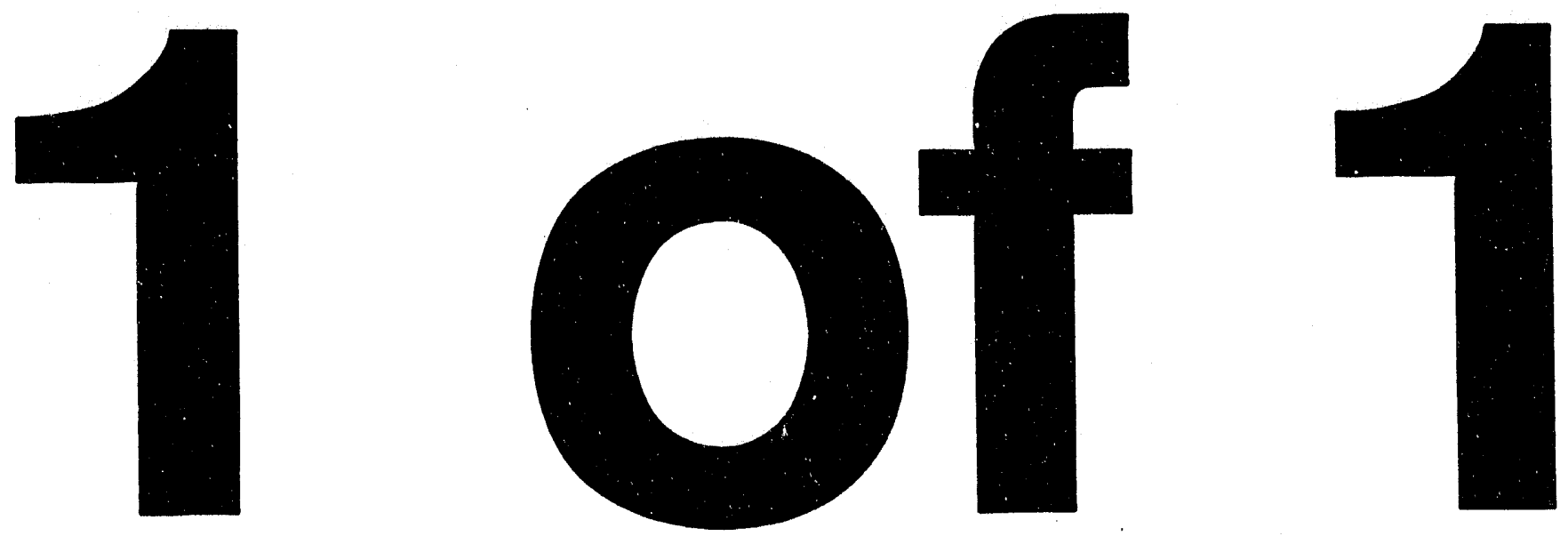


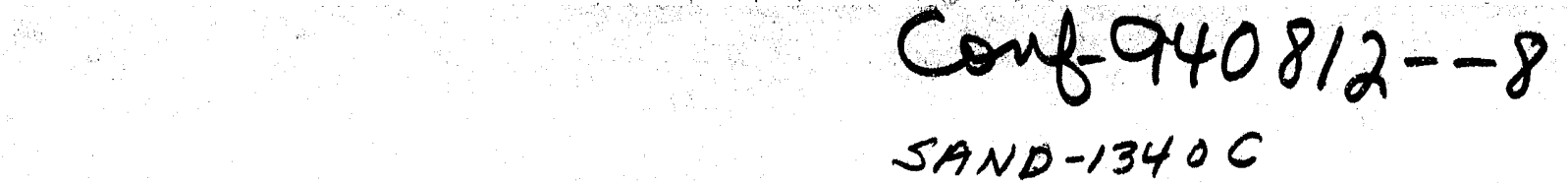

\section{A SOLARIZED BRAYTON ENGINE BASED ON TURBO-CHARGER TECHNOLOGY AND THE DLR RECEIVER}

\author{
Donald R. Gallup \\ Sandia National Laboratories \\ Albuquerque, NM 87185.0703
}

\author{
Jamos B. Kesseli \\ Northern Research \& Engirieering Corp. \\ Woburn, Mass. 01801-2073
}

\begin{abstract}
Northern Research and Engineering Corp. (NREC) is currently under contract to Sandia National Laboratories to solarize a $30 \mathrm{kWe}$ Brayton engine that is based on turbo-charger technology. This program is also supported by the German Aerospace Research Establishment (DLR), which is supplying the solar receiver through an agreement with the International Energy Agency/SolarPACES. The engine is a low pressure, highly recuperated engine. The turbo-machinery is built up from commercial turbo-chargers, which ensures low cost and high reliability. A combustor will be included in the system to allow for full power production during cloud transients. Current estimates are that the engine/alternator thermal-to-electric efficiency will be $30+\%$. The solar receiver to be supplied by DLR will be an advanced version of their VOBREC volumetric receiver. This receiver has a parabolic quartz window and ceramic foam absorber. The estimated efficiency of the receiver is $90+\%$. Sandia has developed an economic model to estimate the levelized energy cost (LEC) of energy produced by dish/engine systems. The model includes both the operating characteristics of the dishes and engines as well as a detailed economic model. The results of the analysis indicate that the dish/Brayton systems compare favorably with dish/Stirling systems.
\end{abstract}

\section{Solar Brayton Cycle Description}

The Brayton/receiver Power Conversion System

This work was performed at Sandia National Laboratories with the sponsorship of the U.S. Department of Energy on Contract No. DEAC04-76DP00789. It is a work of the U.S. Government and not subject ot copyright protection in the United States
(PCS) is composed of the following four major subassemblies:

\section{Solar Receiver \\ Combustor \\ Turbocompressor/Generator \\ Recuperator}

The schematic of the PCS is shown in Figure 1. Ambient air is drawn into a common barrier-type filter. The air then flows into the centrifugal compressor inducer section. The air is discharged radially through a vaned diffuser and exits from the compressor housing duct. This pressurized air continues to diffuse as it enters the cool inlet plenum of the recuperator. Here the air is heated by the waste heat exhausting from the turbine. This preheated air exits the recuperator through a transition duct that connects to the solar receiver.

Within the receiver, air flows at very low velocities through the solar-irradiated foam matrix (solar absorber), acquiring about $350^{\circ} \mathrm{F}$ $\left(200^{\circ} \mathrm{C}\right)$ of sensible heat. A fused silicon dicxide

Figure 1: Flow Diagram of a Solarized Brayton Engine

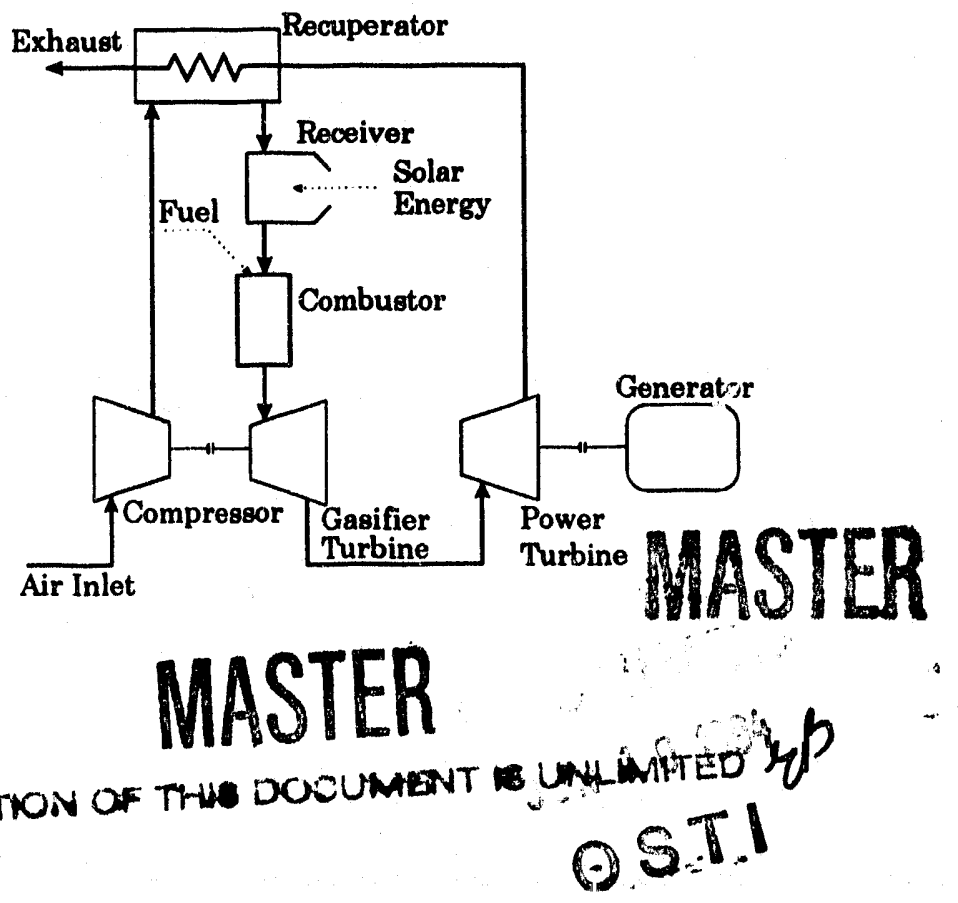


(quartz) window retains the pressurized working fluid which is at nominally 250 to $300 \mathrm{kPa}$. The interior of the receiver is heavily insulated, allowing the exterior shell and pressure vessel to be made of low cost carbon steel or aluminum[2].

After exiting the solar absorber, the air passes through a conventional gas turbine combustor where additional heat may be added to the cycle when there is insufficient solar energy. This "hybrid" capability greatly increases the availability of the electrical power module. Peak power output can be attained both by augmenting the solar energy available during periods of reduced insolation, or during sustained periods when little or no solar energy is available.

The exhaust of the combustor flows through two radial expansion turbines. The first turbine, referred to as the gasifier, drives the cycle's compressor. The second turbine, or power turbine, drives the electrical load through a single stage of gear reduction. The exhaust from the turbine section is decelerated into the recuperator entrance plenum. As these nearatmospheric-pressure gases flow through the recuperator, the receiver inlet air is preheated on the opposite side of the heat exchanger wall. Upon exiting the recuperator the exhaust gas is discharged directly to the environment.

In order to reduce cost and increase reliability, the turbomachinery used in the NREC Brayton engine is built with conventional turbo-charger equipment. For the purposes of this work, the supplier is Schwitzer, although a number of other suppliers could be used.

\section{Performance Analysis}

An overview of the design performance of three different Brayton systems with varying output power levels is presented in this study is presented in Table 1. The efficiencies of the 30 and $62 \mathrm{kWe}$ engines are based on results obtained from component tests and extensive modeling that NREC performed for the Gas Research Institute [1]. The turbine and compressor efficiency for the $18.6 \mathrm{kWe}$ engine were obtained by using Reynolds Number scaling from the larger engines. It should be stressed that the engine operating temperatures and component efficiencies described for use in this study are conservative figures representative of today's industrial quality components and materials. The material selection and manufacturing tolerances are also representative of industrial grade components, and suggest an appropriate balance between cost and efficiency. This is not advanced technology comparable to current aerospace capabilities.

The component efficiency data and projections were used to obtain an algorithm for calculating the efficiency of Brayton engines as a function of their design power. The algorithm obtained is:

Table 1: Overview of the Three Power Systems Analyzed in This Study

\begin{tabular}{|l|l|l|l|}
\hline Baseline Engine Power & $18.6 \mathrm{kWe}$ & $30 \mathrm{kWe}$ & $62 \mathrm{kWe}$ \\
\hline Pressure Ratio & 2.8 & 2.8 & 3.0 \\
Turbine Inlet Temp, K(F) & $1123(1562)$ & $1123(1562)$ & $1123(1562)$ \\
Mass flow rate, kg/s (lbm/s) & $0.230(0.506)$ & $0.345(0.759)$ & $0.640(1.41)$ \\
Compressor Efficiency & 0.79 & 0.8 & 0.8 \\
Gasifier Turbine Efficiency & 0.825 & 0.833 & 0.844 \\
Gasifier Bearing Losses (kW) & 1.649 & 1.753 & 1.753 \\
Power Turbine Efficiency & 0.82 & 0.826 & 0.829 \\
Power Turbine Bearing Loss (kW) & 1.078 & 1.110 & 2.922 \\
Gear Mesh Efficiency & 0.99 & 0.99 & 0.99 \\
Generator Efficiency & 0.93 & 0.93 & 0.93 \\
Recuperator Effectiveness & 0.92 & 0.92 & 0.92 \\
Engine Electric Efficiency & 0.285 & 0.309 & 0.333 \\
\hline
\end{tabular}




$$
\begin{aligned}
\eta(p)= & 0.22842+3.6229 \times 10^{-3} p \\
& -3.1227 \times 10^{-5} p^{2}
\end{aligned}
$$

$\eta$ is the efficiency of the engine at $100 \%$ of the design power, and

$p$ is the engine design power level (kWe) and is in the range of 10 to 62 .

A correction factor must be applied to the engine efficiency if the engine is operating at a reduced power level, i.e., the thermal input power is below the design point. 'ihis correction factor is given by:

$$
\begin{aligned}
C & =0.25540+0.45850 f \\
& +0.89204 f^{2}-0.60589 f^{3}
\end{aligned}
$$

where

$\mathrm{C}$ is the correction factor and

$f$ is the fractional thermal input power above 0.40 .

Below a fractional input power of $40 \%$, the output power is assumed to be zero. This algorithm represents the part-load performance of the specific engine under development for the Gas Industries' small cogeneration program [1]. This application does not generally place a high priority on the part-load electrical efficiency. Relative to recuperated Brayton engines designed for variable speed chiller drives, automobile, or hybrid (electrical) automobile applications, this engine exhibits poorer than usual part-load efficiency. The major compromise for the engine analyzed in this study percains to the selection of a constant speed induction generator. Plots of equations 1 and 2 are given in Figures 2 and 3.

Other findings indicate that a given engine's efficiency is only a function of input thermal power and not directly dependent on ambient temperature. The reason for this is that in the

solar-only mode the turbine inlet temperature is unconstrained and thus is permitted to "float" as power input varies. The turbine and compressor matching analysis showed that at higher ambient temperatures, a higher turbine inlet temperature results. In other words, the efficiency increase resulting from an increase in the cycle high end temperature
Figure 2: Brayton Engine Efficiency as a Function of Engine Design Power

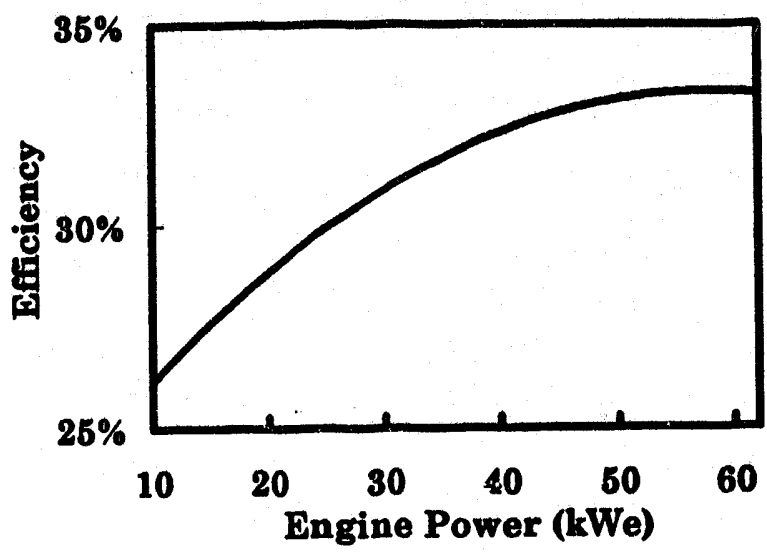

Figure 3: Efficiency Correction Factor for Reduced Thermal Input to Brayton Engine

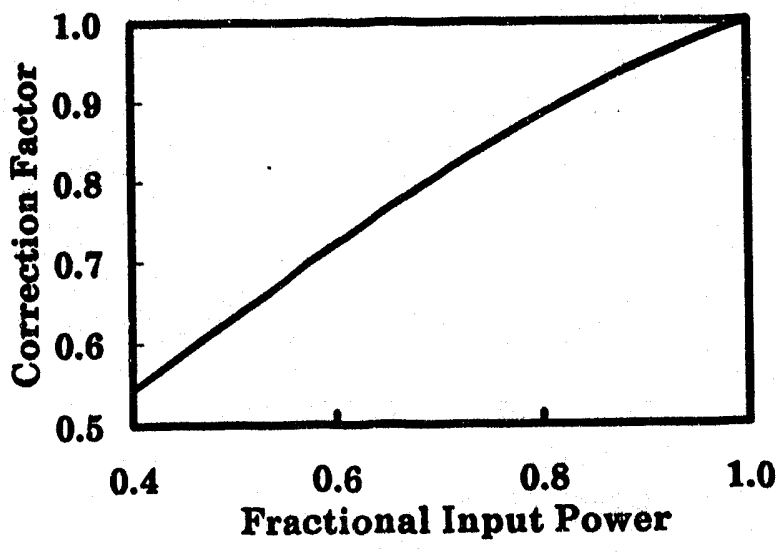

due to increased ambient temperature is offset by the efficiency decrease resulting from an increase in the cycle low side temperature due to the same increased ambient temperature. A rigorous assessment of turbine creep life over the integrated conditions has not yet been completed, however, the majority of the design conditions exhibit Larson-Miller creep life of over 100,000 hours. The creep damage accrued during the worst case turbine inlet conditions, occurring for less that 100 hours per year, appears to be relatively inconsequential.

To derive the combined receiver/engine efficiency, it is necessary to correlate the receiver losses with the inlet and exit temperatures used in the engine analysis. The DLR receiver analysis model, which has been benchmarked against experiments, was used 
to perform this analysis [2]. The results obtained show that the efficiency of the VOBREC volumetric receiver is constant over a wide range of thermal input powers due to the unique quartz window at the receiver aperture. For a receiver designed for use with a $30 \mathrm{kWe}$ engine, tais receiver efficiency ranges from $89.7 \%$ at $50 \%$ power to $90.7 \%$ at $100 \%$ power. The receiver efficiencies for $18.6 \mathrm{kWe}$ and $62 \mathrm{kWe}$ engines were obtained using a parametric analyses; the results of these analyses showed that the efficiencies of these receivers would be similar to the efficiency of the $30 \mathrm{kWe}$ receiver.

\section{Component Costs}

One of the major emphases of this work was to develop a detailed set of component costs for the Brayton PCS for production rates of 100 , 1000 , and 10,000 units/year. Different methods of production that would be used with various production rates were considered, and had a large impact on the overall system cost. For example, the cost of the recuperator for the $30 \mathrm{kWe}$ engine changes from $\$ 2100$ to $\$ 1095$ when production is increased from 100 to 1000 units/year. The Brayton PCS costs developed for this work are presented in Table 2.

\section{Economic Analysis}

The economic analysis performed to estimate the levelized energy cost of dish/Brayton systems was based on a method developed at the Jet Propulsion Laboratory in the mid1970 's [3]. This analysis takes into account the time value of money, the rate of return on debt and equity, the split between debt and equity required by utilities, operation and maintenance (O\&M) costs, fuel costs for hybrid systems, inflation rates (which vary for the various cost components), tax rates, etc. In simplified form, the LEC, in cents per $\mathrm{kWh}$, is given by the equation:

$$
L E C=\frac{F C R_{0} C I+O M+F}{C F_{0} C A P \cdot 8760}
$$

where

FCR is the fixed charge rate,

$\mathrm{CI}$ is the capital investment (cents),

$O M$ is the yearly $O \& M$ cost (cents),

$F$ is the yearly fuel cost (cents),

$\mathrm{CF}$ is the system capacity factor,

CAP is the system output power (kWe), \&

8760 is the number of hours per year.

The fixed charge rate is a multiplier that includes both the yearly cost of paying off the capital equipment and property taxes and insurance, which are typically based on the cost of the capital investment. The denominator in Equation 1 is the amount of electrical energy in $\mathrm{kWh}$ produced by the power system in one year. In order to accurately calculate this value, it is necessury to have colar insolation data, i.e., insolation values and duration of that insolation during a typical meteorological year (TMY), for the particular site under consideration. In addition, since the thermal input power to the engine will vary as the solar insolation varies, data on the engine efficiency as a function of thermal input power is also required. When this data is combined, the energy produced in a year can be calculated. Table 3 shows how this calculation is performed for a solar-only system.

The capital equipment costs for the PCS were presented earlier. In order to calculate the cost of the concentrator, it is assumed that the

Table 2: Brayton PCS Selling Price for Various Power Levels and Production Rates

\begin{tabular}{|l|r|r|r|r|r|r|r|r|r|}
\hline & \multicolumn{3}{|c|}{$18.6 \mathrm{~kW}$} & \multicolumn{3}{c|}{$30 \mathrm{~kW}$} & \multicolumn{3}{|c|}{$62 \mathrm{~kW}$} \\
\cline { 2 - 10 } Component & \multicolumn{1}{|c|}{100} & \multicolumn{1}{|c|}{1000} & 10000 & \multicolumn{1}{c|}{100} & \multicolumn{1}{c|}{1000} & 10000 & \multicolumn{1}{c|}{100} & 1000 & 10000 \\
\hline Receiver & $\$ 7290$ & $\$ 6900$ & $\$ 6645$ & $\$ 10830$ & $\$ 10245$ & $\$ 9870$ & $\$ 20760$ & $\$ 19650$ & $\$ 18930$ \\
Engine & 7372 & 5737 & 4485 & 8662 & 6397 & 5100 & 11662 & 7657 & 6570 \\
Lubricate Syst & 1950 & 1650 & 1500 & 1950 & 1650 & 1500 & 1950 & 1650 & 1500 \\
Gear Box & 4800 & 4200 & 3300 & 4800 & 4200 & 3300 & 4800 & 4200 & 3300 \\
Generator & 577.5 & 562.5 & 532.5 & 967.5 & 945 & 892.5 & 2700 & 2400 & 2250 \\
Packaging & 3201 & 2638 & 2100 & 3201 & 2638 & 2100 & 3337 & 2757 & 2175 \\
\hline Total & 25191 & 21688 & 18562 & 30411 & 26076 & 22762 & 45210 & 38314 & 34725 \\
\hline
\end{tabular}


Table 3: Example Calculation of Energy Produced By a $30 \mathrm{kWe}$ Solar-Only Dish/Brayton System Using Albuquerque, NM TMY Data

\begin{tabular}{|c|c|c|c|c|c|c|c|}
\hline $\begin{array}{c}\text { Insolation } \\
(W / \mathrm{m} 2)\end{array}$ & $\begin{array}{r}\text { Time } \\
\text { hrs/yr }\end{array}$ & $\begin{array}{r}\text { Dish } \\
(\mathrm{kWt})\end{array}$ & $\begin{array}{r}\text { Combustor } \\
(\mathrm{kWt})\end{array}$ & $\begin{array}{l}\text { Qeng } \\
(k W t)\end{array}$ & $\begin{array}{l}\text { Peng } \\
\text { (kWe) }\end{array}$ & $\begin{array}{r}\text { Pnet } \\
(\mathrm{kWe})\end{array}$ & $\begin{array}{r}\text { Energy } \\
(\mathrm{kWh})\end{array}$ \\
\hline 0.100 & 5089 & 0 & 0 & 0 & 0 & 0 & $\overline{0}$ \\
\hline $100-200$ & 276 & 0.00 & 0.00 & 0.00 & 0.00 & 0.00 & 0.00 \\
\hline $200 \cdot 300$ & 201 & 0.00 & 0.00 & 0.00 & 0.00 & 0.00 & 0.00 \\
\hline $300-400$ & 216 & 0.00 & 0.00 & 0.00 & 0.00 & 0.00 & 0.00 \\
\hline $400 \cdot 500$ & 181 & 64.41 & 0.00 & 46.44 & 8.81 & 7.81 & 1414 \\
\hline $500 \cdot 600$ & 229 & 78.73 & 0.00 & 56.76 & 12.43 & 11.48 & 2617 \\
\hline $600 \cdot 700$ & 261 & 93.04 & 0.00 & 67.08 & 16.57 & 15.57 & 4065 \\
\hline $700 \cdot 800$ & 444 & 107.35 & 0.00 & 77.40 & 21.10 & 20.10 & 8925 \\
\hline $800 \cdot 900$ & 674 & 121.67 & 0.00 & 87.72 & 25.82 & 24.82 & 16726 \\
\hline $900 \cdot 1000$ & 1021 & 135.98 & 0.00 & 98.04 & 30.46 & 29.46 & 30082 \\
\hline $1000 \cdot 1100$ & 168 & 147.43 & 0.00 & 106.30 & 32.93 & 29.00 & 5582 \\
\hline & & & & & & $\begin{array}{l}\text { Gross kWh } \\
\text { Net kWh } \\
\text { Avail. } \mathrm{kWh}\end{array}$ & $\begin{array}{l}72339 \\
69361 \\
65893\end{array}$ \\
\hline
\end{tabular}

cost per unit area of the concentrator is constant over the range of 67 to $230 \mathrm{~m}^{2}$. For production rates of 100,1000 , and 10,000 units per year, the cost of the concentrator was assumed to be 450,225 , and $150 \$ / \mathrm{m}^{2}$, respectively. The concentrator size is backcalculated based on a design insolation level, average mirror reflectivity, receiver intercept factor, receiver efficiency, engine gross power, and engine efficiency. The control system cost is assumed to be $\$ 10,000, \$ 7500$, and $\$ 5000$ per system, respectively, for the above production rates. Finally, the shipping and installation costs are assumed to be $\$ 2500$, $\$ 2000$, and $\$ 1725$ per system, respectively, for the above production rates. The values for these three balance of system components are consistent with values being used in the Utility Scale Joint Venture Program [4].

The estimated O\&M costs for the dish/Brayton system were obtained evaluating the O\&M costs for each of the components. The costs varied between 0.8 and 1.0 cents $/ \mathrm{kWh}$ with system size. For hybrid systems, the fuel costs were calculated based on a natural gas price of $\$ 3.00$ per MBtu. For a $30 \mathrm{kWe}$ engine, with $25 \%$ of the power produced by gas, the yearly fuel cost is $\sim \$ 1000$, which corresponds to $\sim 1.8$ cents/kWh.
The LECs obtained in the economic analysis are presented in Tables 4 and 5 for hybrid and solar-only systems, respectively. The best benchmarks for determining the economic viability of dish/Brayton systems as compared to dish/Stirling systems come from the USJVP. For dish/Stirling systems that produce approximately $25 \mathrm{kWe}$ of gross engine power, the LEC of a hybrid system will be in the range of 6 to 9 cents/kWh at production rates of 10,000 systems per year[4]. From Table 4, it is seen that the estimated cost of a $30 \mathrm{kWe}$

Table 4: LEC (cents/kWh) for Dish/Brayton Power Systems With 25\% Natural Gas Energy Production

\begin{tabular}{|c|r|r|r|}
\hline Engine & \multicolumn{3}{|c|}{ System Production Rate (y-1) } \\
\cline { 2 - 4 } Power (kW) & \multicolumn{1}{|c|}{100} & 1000 & 10,000 \\
\hline 18.5 & 14.9 & 10.6 & 8.6 \\
\hline 30.0 & 11.7 & 8.1 & 6.5 \\
\hline 62.0 & 9.2 & 6.0 & 4.9 \\
\hline
\end{tabular}

Table 5: LEC (cents/kWh) for Solar-Only Dish/Brayton Power Systems

\begin{tabular}{|c|r|r|r|}
\hline Engine & \multicolumn{3}{|c|}{ System Production Rate $\left(\mathrm{y}^{\cdot} \cdot \mathrm{l}\right)$} \\
\cline { 2 - 4 } Power $(\mathrm{kW})$ & \multicolumn{1}{|c|}{100} & \multicolumn{1}{|c|}{1000} & 10,000 \\
\hline 18.5 & 21.8 & 14.9 & 11.8 \\
\hline 30.0 & 16.8 & 11.0 & 8.7 \\
\hline 62.0 & 13.0 & 8.0 & 6.1 \\
\hline
\end{tabular}


gross dish/Brayton system is estimated to be 6.5 cents $/ \mathrm{kWh}$. This falls in the lower part of the range for the dish/Stirling LEC estimates.

Based on these economic results and other factors, Cummins Power Generation, Inc. has decided to include the Brayton PCS as a back. up in their USJVP. This will result in a rigorous test of the Brayton $\mathrm{PCS}_{8}$ actual capabilities.

\section{Conclusions}

All components necessary to build a solarized Brayton PCS currently exist, and a design is being developed to build such a system. Further, economic analyses that were performed for dish/Brayton systems on a consistent basis with analyses performed for dish/Stirling systems indicate that the Brayton PCS competes very well with the Stirling PCS. Over the next two years, the actual ability of dish/Brayton systems to compete economically will be determined.

\section{References}

1. Kesseli, et al, "Low Nox Combustor Design and Test with a Recuperated Gas Turbine Engine, ASME IGTI Vol. 7 Book No. 100333-1992.

2. Heller, et al, "Development of a Volumetric Receiver for a Dish.Brayton System," Solar Engineering 1994, March 1994, pp. 561 . 566.

3. Doane, st al, The Cost of Energy from Utility-()wned Solar Electric Systems, JPL-5C40-29, June 1976.

4. Gailup, et al, "Utility Scale Joint Venture Program," IECEC '94, to be published. 

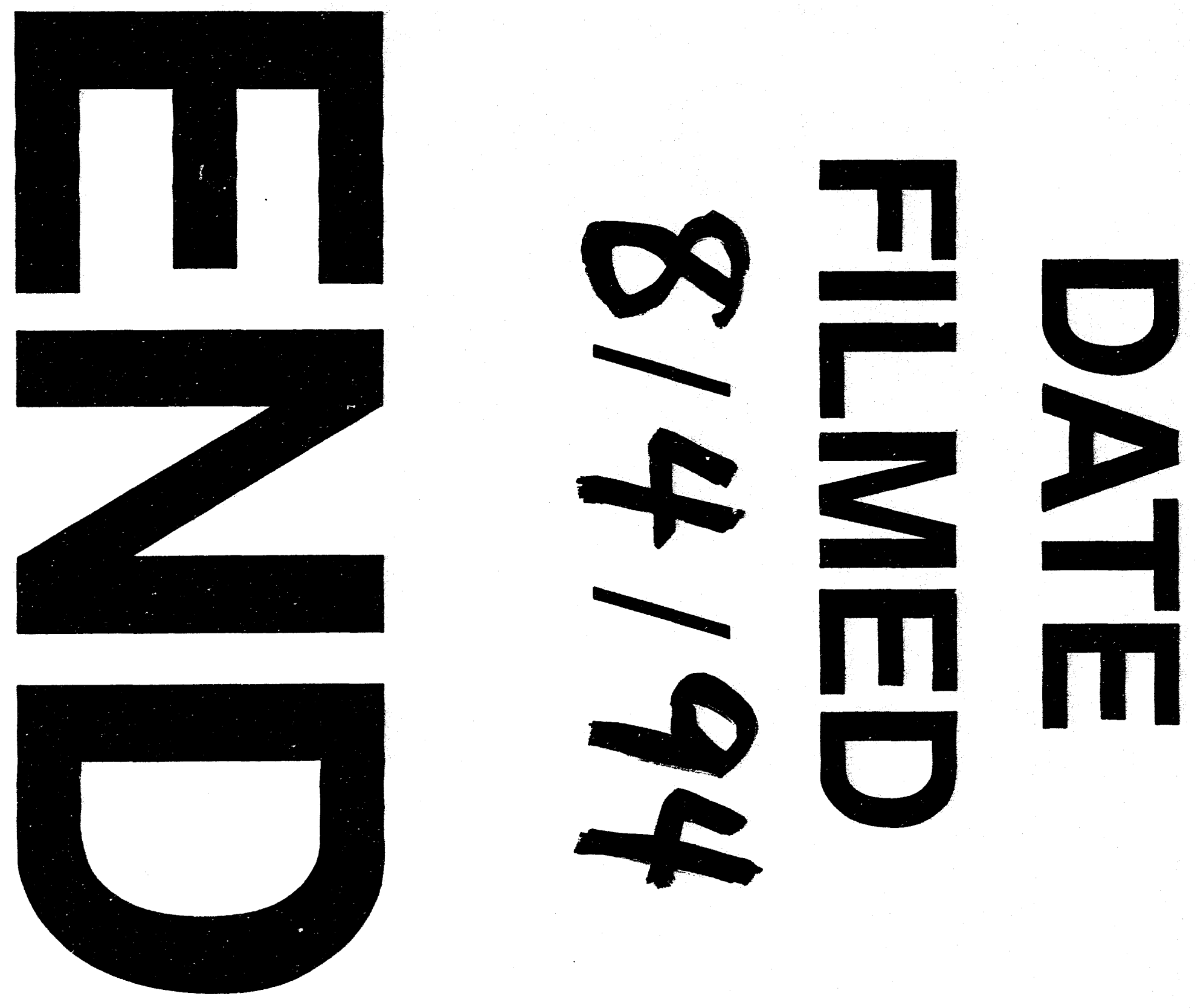


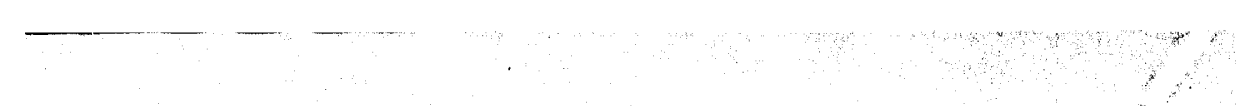

